\title{
Preparation and properties of the $(\mathrm{Sr}, \mathrm{Ba}) \mathrm{Nb}_{2} \mathrm{O}_{6}$ thin films by using the sputtering method
}

\author{
Chien-Chen Diao ${ }^{1}$, Cheng-Fu Yang ${ }^{2}$, and Chia-Ching $\mathrm{Wu}^{1, *}$ \\ ${ }^{1}$ Department of Electronic Engineering, Kao Yuan University, Kaohsiung, Taiwan \\ ${ }^{2}$ Department of Chemical and Materials Engineering, National University of Kaohsiung, Kaohsiung, Taiwan
}

\begin{abstract}
Strontium barium niobate $\left(\mathrm{Sr}_{0.3} \mathrm{Ba}_{0.7} \mathrm{Nb}_{2} \mathrm{O}_{6}, \mathrm{SBN}\right)$ thin films were deposited on silicon substrate by using the radio frequency magnetron sputtering and under different deposition power and time at room temperature. Surface morphology and thicknesses of the SBN thin films were characterized by field emission scanning electron microscopy. The crystallization films at different deposition power and time were analyzed by $\mathrm{X}$-ray diffraction (XRD) using $\mathrm{CuK} \alpha$ radiation from a Rigaku rotating anode with an incident angle of $2^{\circ}$. The remnant polarization ( $\mathrm{Pr}$ ), saturation polarization (Ps), and minimum coercive field (Ec) properties of the metal-ferroelectric-metal (MFM) structure were measured using ferroelectric material test instrument. The SBN thin films deposited at $90 \mathrm{~min}$ and $125 \mathrm{~W}$ had the maximum Pr, Ps, and minimum Ec of $1.26 \mu \mathrm{C} / \mathrm{cm}^{2}, 2.41 \mu \mathrm{C} / \mathrm{cm}^{2}$, and $201.6 \mathrm{kV} / \mathrm{cm}$, respectively. From above results, it knows that the SBN thin films suit for application on ferroelectric random access memory (FeRAM).
\end{abstract}

\section{Introduction}

Ferroelectric materials are an important class of materials whose main characteristic is the presence of a spontaneous polarization that can be changed with an external electric field. The tungsten bronze family is one of several ferroelectric materials that includes niobates such as $(\mathrm{Sr}, \mathrm{Ba}) \mathrm{Nb}_{2} \mathrm{O}_{6}(\mathrm{SBN}),(\mathrm{Pb}, \mathrm{Ba}) \mathrm{Nb}_{2} \mathrm{O}_{6}(\mathrm{PBN})$ and $(\mathrm{Pb}, \mathrm{K}) \mathrm{Nb}_{2} \mathrm{O}_{6}$ (PKN). In February 2003, the European Union adopted the Restriction of Hazardous Substances (RoHS) directive, limiting the use of certain hazardous substances in electrical and electronic equipment. In accordance with environmental concerns and to avoid problems related to use of lead $(\mathrm{Pb})$, researchers have moved toward using lead-free materials. The SBN is a lead-free ferroelectric material, widely considered very useful in diverse device applications, including memory devices [1], waveguide devices [2], and others. An important representing of ferroelectric material is the SBN, known by excellent pyroelectric coefficient [3, 4], piezoelectric [5] and electro optic properties [6, 7]. SBN presents a tetragonal or orthorhombic phase, depending of composition and temperature.

The SBN solid-solution series crystallize in the tetragonal tungsten bronze (TTB) structure. At room temperature it has the symmetry of the space group P4bm for $0.25<x<0.75$. It belongs to the $4 \mathrm{~mm}$ point group in the ferroelectric phase and changes to the $4 / \mathrm{mmm}$ when in the paraelectric phase. Investigation of $\mathrm{Sr}_{\mathrm{x}} \mathrm{Ba}_{1-\mathrm{x}} \mathrm{Nb}_{2} \mathrm{O}_{6}$ ceramics using $\mathrm{X}$-ray diffraction suggests that a morphotropic phase boundary (MPB) exist at round the composites of $\mathrm{Sr}_{0.25} \mathrm{Ba}_{0.75} \mathrm{Nb}_{2} \mathrm{O}_{6}$, which is characterized by the coexistence of the tetragonal and orthorhombic phases [8]. $\quad \mathrm{Sr}_{0.2} \mathrm{Ba}_{0.8} \mathrm{Nb}_{2} \mathrm{O}_{6}$ ceramic presents a tetragonal ferroelectric phase between 120 and $293^{\circ} \mathrm{C}$, an orthorhombic phase below $120^{\circ} \mathrm{C}$ and a tetragonal paraelectric phase above $293^{\circ} \mathrm{C}$.

SBN thin films have been prepared by several techniques like sol-gel processing [9], pulsed laser deposition [10] and metalorganic chemical vapor deposition (MOCVD) [11]. Recently, it has been proposed to prepare SBN thin films by a chemical method based on a polymeric resin containing metallic ions [12]. However, the radio frequency (RF) magnetron sputtering is a simple method to deposit the needed thin films [13]. In the research, $\mathrm{Sr}_{0.7} \mathrm{Ba}_{0.3} \mathrm{Nb}_{2} \mathrm{O}_{6}(\mathrm{SBN})$ thin films were obtained by a radio frequency (RF) magnetron sputtering method at room temperature. The influence of deposition power and time on the crystallinity and ferroelectricity of SBN thin films was studied using the analysis of scanning electron microscopy and X-ray diffraction, and the measured of leakage current and polarization, respectively.

\section{Experimental procedures}

The conventional solid-state reaction method was used to prepare the $\mathrm{Sr}_{\mathrm{x}} \mathrm{Ba}_{1-\mathrm{x}} \mathrm{Nb}_{2} \mathrm{O}_{6}, \mathrm{x}=0.3$ ( $\mathrm{SBN}$ ) ceramic. Reagent-grade oxide or carbonate powders of $\mathrm{SrCO}_{3}$, $\mathrm{BaCO}_{3}$, and $\mathrm{Nb}_{2} \mathrm{O}_{5}$ with greater than $99.5 \%$ purity were used as starting raw materials. The oxides were mixed with deionized water by ball-milling for $1 \mathrm{~h}$. After drying and grinding, the powder was calcined at $1100{ }^{\circ} \mathrm{C}$ for $2 \mathrm{~h}$, and the formation of the tungsten bronze structure was confirmed by the XRD pattern. Then, ground again and mixed with polyvinyl alcohol (PVA)

\footnotetext{
*Corresponding author: t10068@cc.kyu.edu.tw
} 
as binder. the calcined powder was uniaxially pressed in a steel die into a 2-inch disk, and the ceramic was sintered at $1340{ }^{\circ} \mathrm{C}$ in air for $2 \mathrm{~h}$. The SBN thin films were deposited under various deposition power and time on a silicon wafer by an radio frequency (RF) sputtering method. The deposition pressure was $5 \times 10^{-3}$ torr, and pure argon (Ar) was used as the reaction gas. Finally, the aluminum (Al) top electrodes were deposited by an electron beam evaporation method on the SBN thin films, with a $1 \mathrm{~mm}$ diameter shadow mask, to form the metalferroelectric-metal (MFM) structures. The structure of the SBN ceramic and thin films were analyzed by X-ray diffraction (XRD) using $\mathrm{CuK} \alpha$ radiation from a Rigaku rotating anode with an incident angle of $2^{\circ}$. Field emission scanning electron microscopy (FE-SEM) was used to study the surface morphologies of the SBN ceramic and thin films. The leakage current density versus applied electric field (J-E) was measured using an HP 4156 semiconductor parameter analyzer. The saturation polarization, remanent polarization, and coercive field properties of the MFM structure were measured using ferroelectric material test instrument.

\section{Results and discussion}

The FE-SEM morphology of $1340{ }^{\circ} \mathrm{C}$ sintered SBN ceramic as shown in Fig. 1. In Fig. 1, as the SBN ceramic sintered at $1340^{\circ} \mathrm{C}$, the several bar-type grains developed and no any pores are observed. Figure 2 shows the X-ray diffraction (XRD) patterns of $1340{ }^{\circ} \mathrm{C}$ sintered SBN ceramic in the $2 \theta$ range of 20 to $80^{\circ}$ as shown in Fig. 2. The XRD results revealed at $2 \theta$ values of $22.4^{\circ}, 25.6^{\circ}, 27.6^{\circ}, 28.3^{\circ}, 29.3^{\circ}, 30.3^{\circ}, 31.9^{\circ}, 34.2^{\circ}$, $36.6^{\circ}, 38.9^{\circ}, 42.1^{\circ}, 45.8^{\circ}, 48.7^{\circ}, 49.4^{\circ}, 51.5^{\circ}, 52.3^{\circ}, 53.5^{\circ}$, $54.3^{\circ}, 55.4^{\circ}$ and $57.1^{\circ}$ were corresponded to the $(001)$, (320), (221), (440), (410), (221), (331), (321), (401), (520), (530), (260), (630), (601), (550), (541), (332), (631), (412) and (711) planes of SBN ceramic, respectively. No second phase was present in this ceramic.

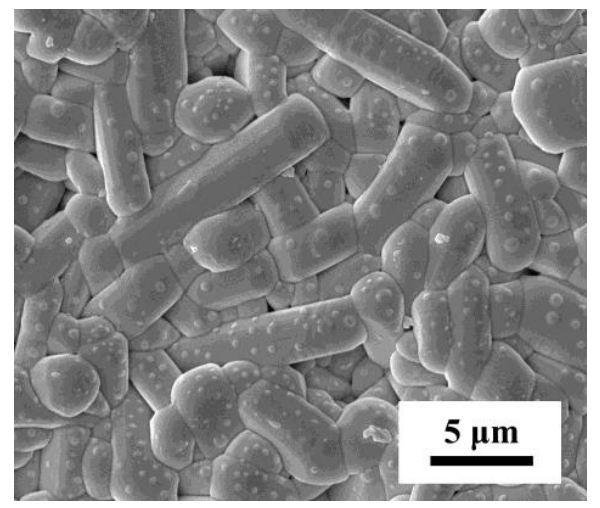

Fig. 1. SEM images of the SBN ceramic sintered at $1340{ }^{\circ} \mathrm{C}$.

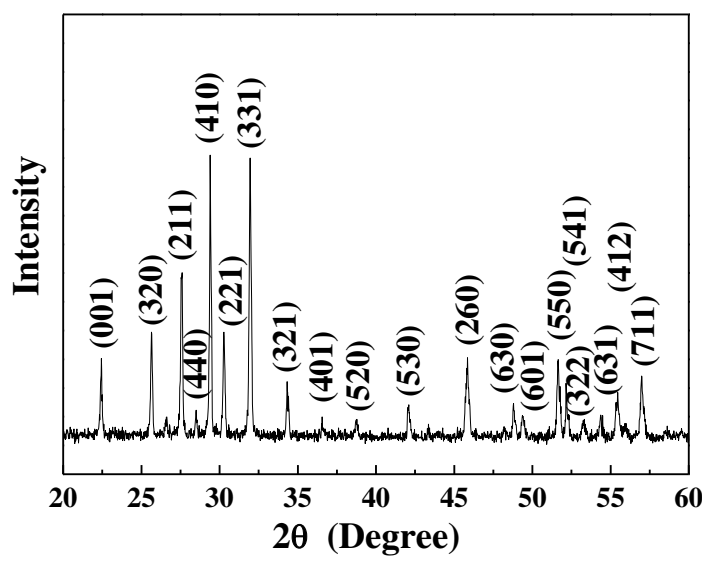

Fig. 2. XRD patterns of the $\mathrm{SBN}$ ceramic sintered at $1340^{\circ} \mathrm{C}$.

Figure 3 shows the temperature dependence on the dielectric constants $\left(\varepsilon_{\mathrm{r}}-\mathrm{T}\right)$ of the SBN ceramic sintered at $1340{ }^{\circ} \mathrm{C}$. It fount that the dielectric constant increased as the measured temperature increased at $135^{\circ} \mathrm{C}$, than, the dielectric constant decreased as the measured temperature increases from 140 to $200{ }^{\circ} \mathrm{C}$. The SBN ceramic have a dielectric peak $\left(\mathrm{K}_{\max }\right)$ at $135^{\circ} \mathrm{C}$, which is the Curie temperature $\left(\mathrm{T}_{\mathrm{c}}\right)$ of $\mathrm{SBN}$ ceramic, and the maximum dielectric constant is $\varepsilon_{\mathrm{r}}=4322$.

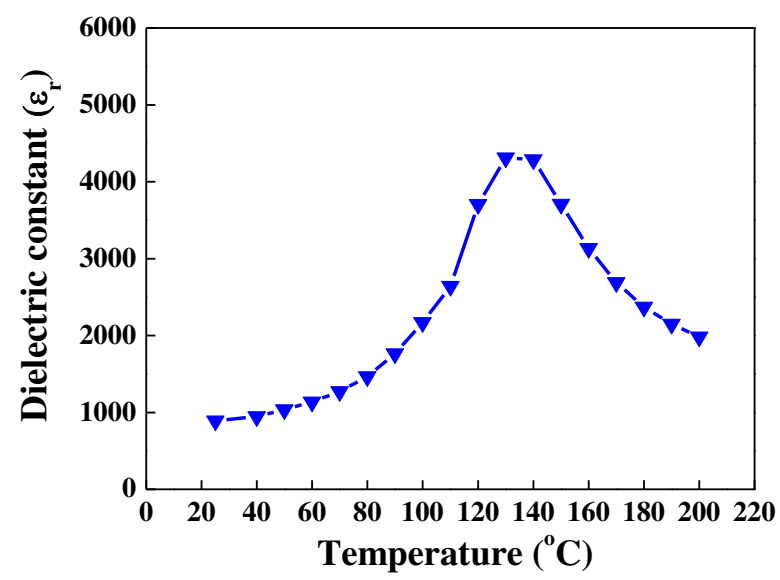

Fig. 3. Temperature dependence on the dielectric constants of the SBN ceramic sintered at $1340{ }^{\circ} \mathrm{C}$.

Figure 4 shows surface FE-SEM images of the SBN thin films with different deposition power. The SBN surface morphology varies greatly with the different sputtering power, as shown in Fig. 4(a) to Fig. 4(d). In the case of the SBN thin film deposited at $75 \mathrm{~W}$ (Fig. $2(a)$ ), the surface is smooth and no grain growth is observable. Because the kinetic energy of the sputtered particles arriving at the substrate surface is weak. As the deposition power increases from $75 \mathrm{~W}$ to $125 \mathrm{~W}$, the surface roughness of the SBN thin films slightly increased, and no grain growth is observable. However, the grain in the SBN thin film was observed as the deposited power at $150 \mathrm{~W}$. 

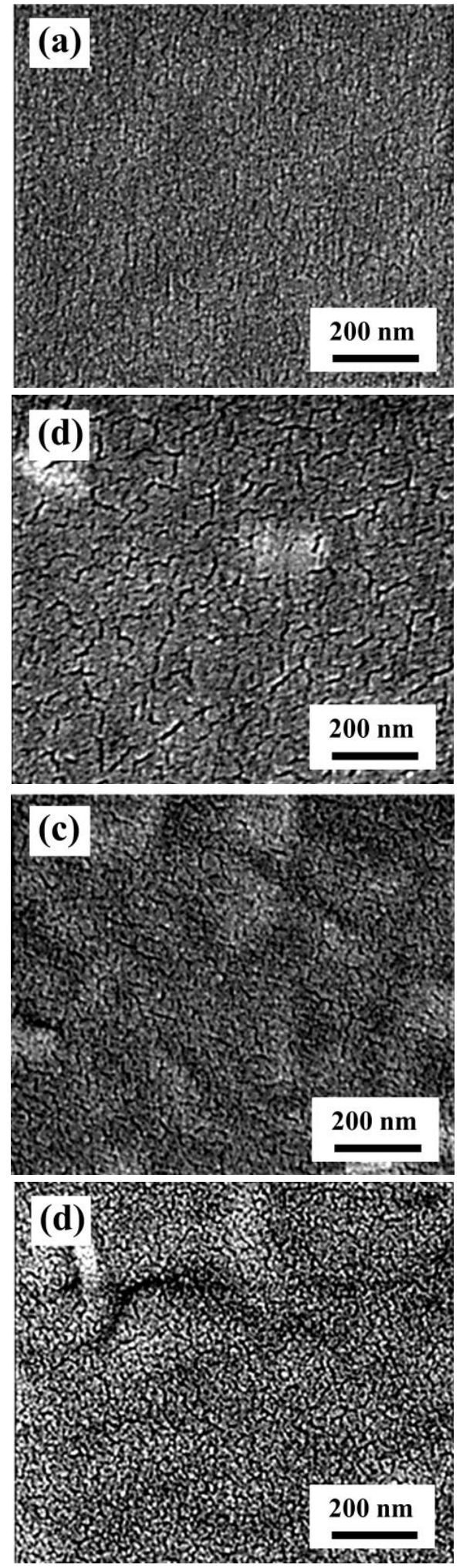

Fig. 4. SEM images of the SBN thin films deposited with different power. (a) $75 \mathrm{~W}$, (b)100 W, (c) $125 \mathrm{~W}$ and (d)150 W.

Figure 5 shows the influence of deposition power on the thickness of the SBN thin films. At deposition power were $75,100,125$ and $150 \mathrm{~W}$, the thickness of the SBN thin films were $277.19,333.33,350.87$, and $282.46 \mathrm{~nm}$, respectively. The thinckness of the SBN thin films increased as the depoaition power increases from $75 \mathrm{~W}$ to $125 \mathrm{~W}$. This results cause by the number of sputtered particles arriving at the substrate increased. As the deposition power increasing from $125 \mathrm{~W}$ to $150 \mathrm{~W}$, the thinckness of the SBN thin film decreased. This results cause by the higher energy of sputtered particles arriving at the substrate and etching the film surface as the deposition power at $150 \mathrm{~W}$.

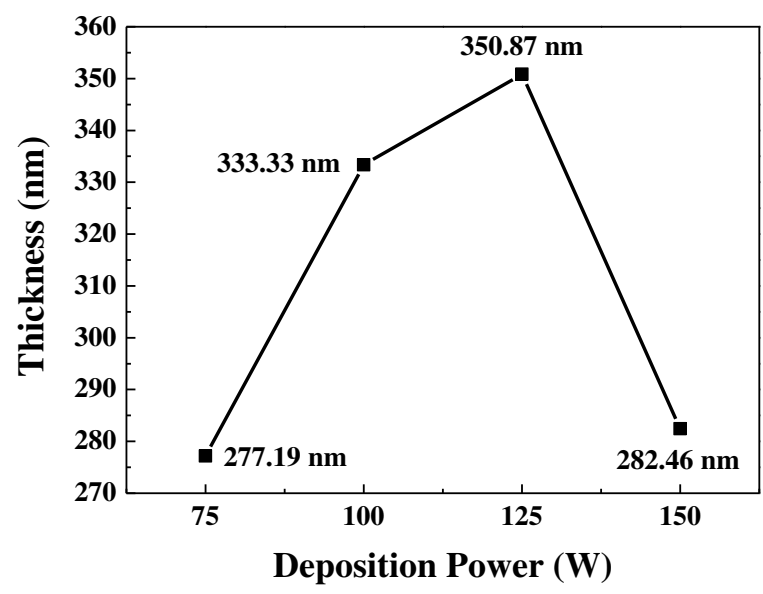

Fig. 5. Thickness of the SBN thin films deposited with different power.

The XRD analysis of the SBN thin films deposited at different power are shown in Fig. 6. All the SBN thin films showed an amorphous structure because they were deposited at room temperature. Figure 6(a) is the standard peak of the aluminum (Al). A crystalline peak of $38.5^{\circ}$ is revealed in the $\mathrm{Al}$ electrode, and the diffraction peaks' intensity decreases as the deposition power increases from 75 to $150 \mathrm{~W}$, as shown in Figs. 6(b) to 6(e). This result confirms that the thickness of the SBN thin films increases as the deposition power increases from $75 \mathrm{~W}$ to $150 \mathrm{~W}$.

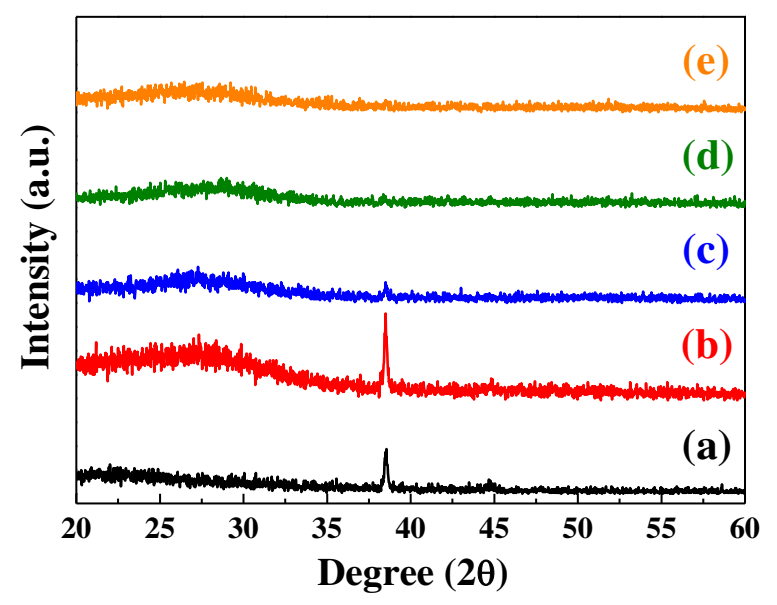

Fig. 6. XRD analysis of the SBN thin films deposited with different power. (a) standard peak, (b) $75 \mathrm{~W}$, (c)100 W, (d)125 $\mathrm{W}$ and (e) $150 \mathrm{~W}$.

Figure 7 shows the leakage current density versus electrical field (J-E) curves of the SBN thin films 
deposited with different power. The leakage current density of the SBN thin films slightly decreased as the deposition power increased from $75 \mathrm{~W}$ to $125 \mathrm{~W}$. There are many reasons will influence the leakage current densify, including the thickness and defects of the deposited this films $[14,15]$.

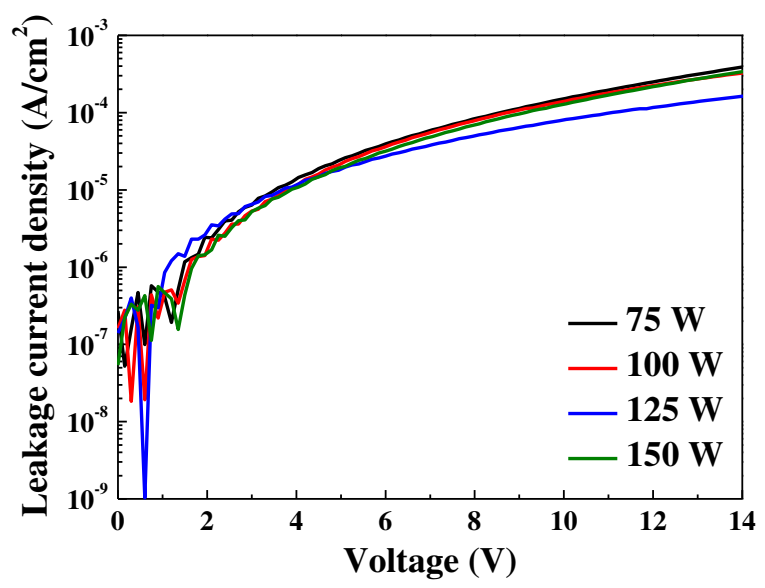

Fig. 7. Leakage current density of the SBN thin films deposited with different power.

Figure 8 shows surface FE-SEM images of the SBN thin films with different deposition time. In the case of the SBN thin film deposited at $30 \mathrm{~min}$, the surface is smooth and no grain growth is observable as shown in Fig. 8. As the deposition time increases from 60 to 120 min, the surface roughness of the SBN thin films increased, and grain growth is observable at the $120 \mathrm{~min}$ deposition time.

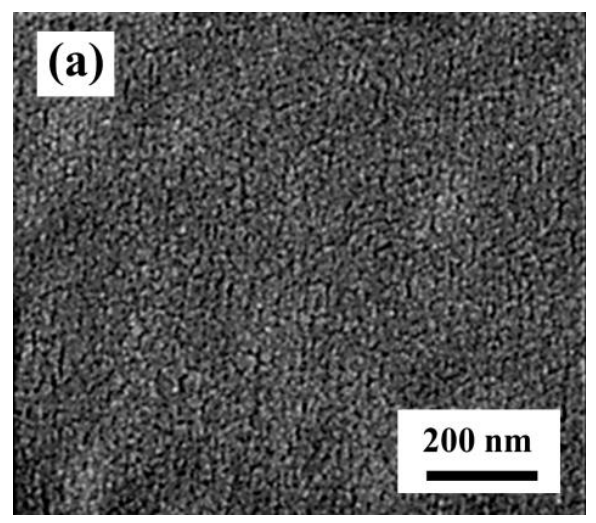

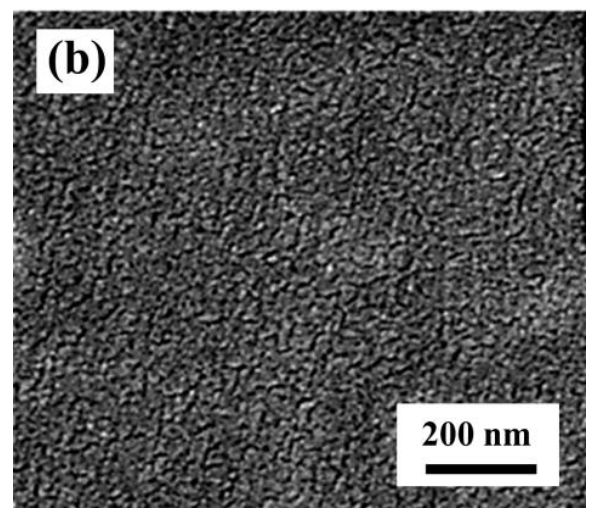
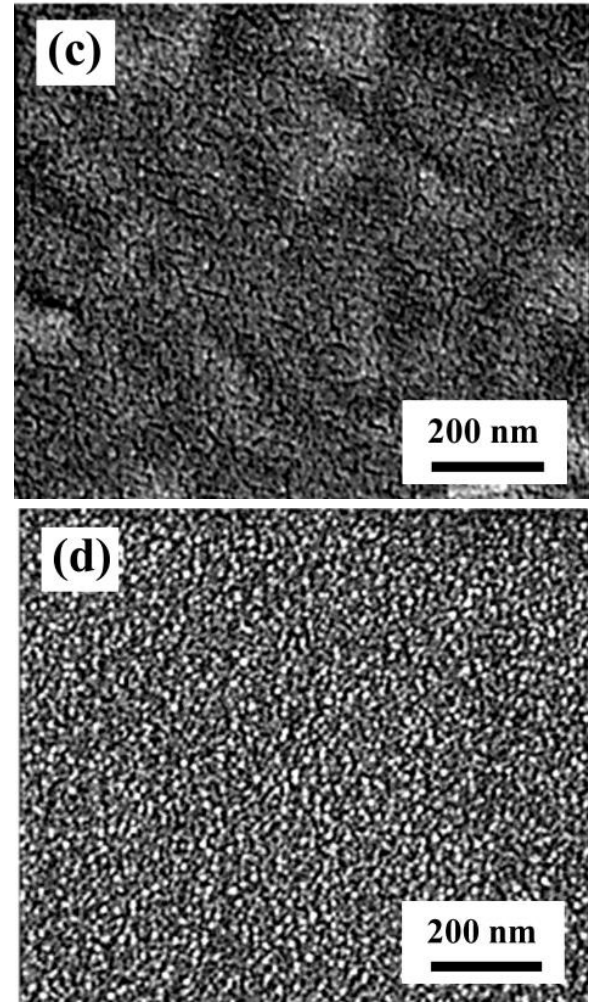

Fig. 8. SEM images of the SBN thin films deposited with different time. (a) $30 \mathrm{~min}$, (b) $60 \mathrm{~min}$, (c) $90 \mathrm{~min}$ and (d) 120 min.

Figure 9 shows the influence of deposition time on the thickness of the SBN thin films. At deposition times were $30,60,90$ and $120 \mathrm{~min}$, the thickness of the SBN thin films were $175.43,189.47,292.98$, and $350.87 \mathrm{~nm}$, respectively. The thinckness of the SBN thin films increased as the depoaition times increases from $30 \mathrm{~min}$ to $120 \mathrm{~min}$. This results cause by the number of sputtered particles arriving at the substrate increased as the deposition time increased. 


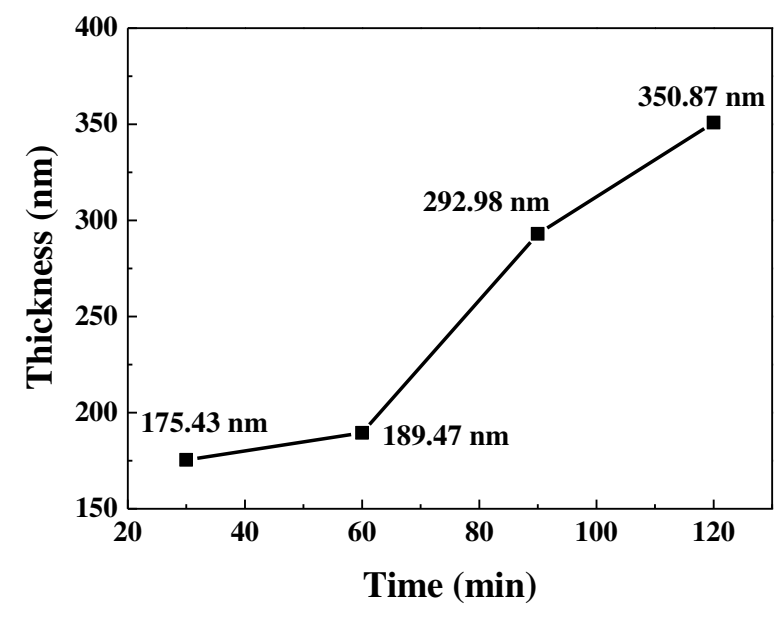

Fig. 9. Thickness of the SBN thin films deposited with different time.

The XRD analysis of the SBN thin films deposited at different time are shown in Fig. 10. All the SBN thin films showed an amorphous structure because they were deposited at room temperature. A crystalline peak of $38.5^{\circ}$ is revealed in the $\mathrm{Al}$ electrode, and the diffraction peaks' intensity decreases as the deposition time increases from $30 \mathrm{~min}$ to $120 \mathrm{~min}$, as shown in Figs. 10(a) to $10(\mathrm{~d})$. This result confirms that the thickness of the $\mathrm{SBN}$ thin films increases as the deposition time increases from $30 \mathrm{~min}$ to $120 \mathrm{~min}$.

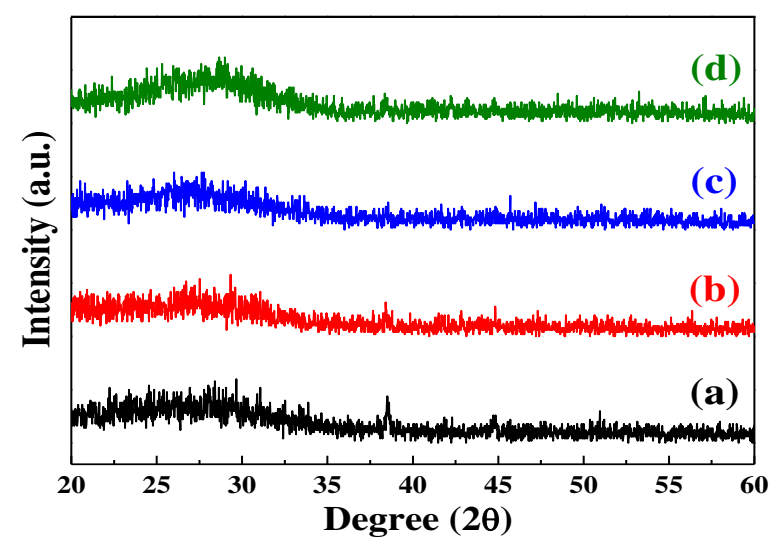

Fig. 10. XRD analysis of the SBN thin films deposited with different time. (a) $30 \mathrm{~min}$, (b) $60 \mathrm{~min}$, (c) $90 \mathrm{~min}$ and (d) 120 min.

Figure 11 shows the leakage current density versus electrical field (J-E) curves of the SBN thin films deposited with different time. The leakage current density of the SBN thin films decreased as the deposition time increased from $30 \mathrm{~min}$ to $90 \mathrm{~min}$. As the deposition at $120 \mathrm{~min}$, the leakage current density of the SBN thin films slightly increased. The larger leakage current density led to less residual charge in the ferroelectric layer.

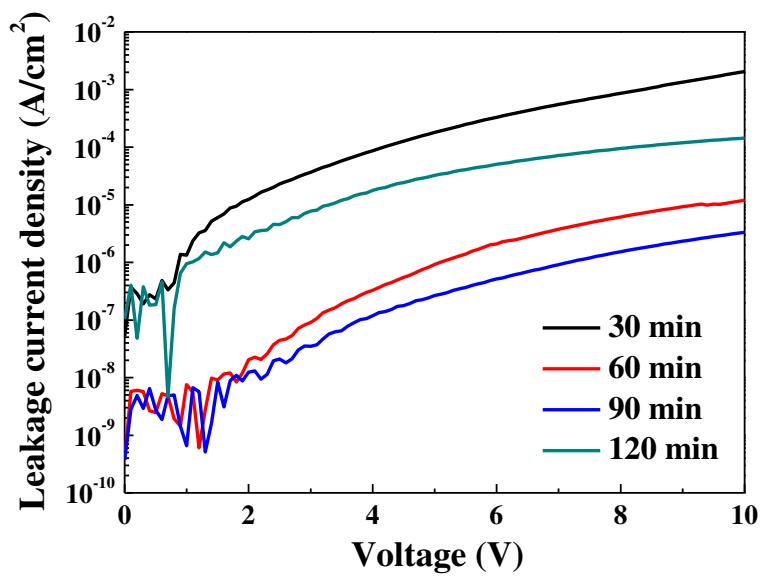

Fig. 11. Leakage current density of the SBN thin films deposited with different time.

Figure 12 shows the polarization versus applied electrical field (P-E) curves of the SBN thin film. The development of hysteresis loops in the SBN thin film confirms the ferroelectric nature. The SBN thin films deposited at $90 \mathrm{~min}$ and $125 \mathrm{~W}$ had the maximum remnant polarization (Pr), saturation polarization (Ps), and minimum coercive field (Ec) of $1.26 \mu \mathrm{C} / \mathrm{cm}^{2}, 2.41$ $\mu \mathrm{C} / \mathrm{cm}^{2}$, and $201.6 \mathrm{kV} / \mathrm{cm}$, respectively. The Pr, Ps and Ec values of the SBN thin film deposited at $90 \mathrm{~min}, 125$ $\mathrm{W}$ and room temperature are slightly larger than those in other reports [22-24].

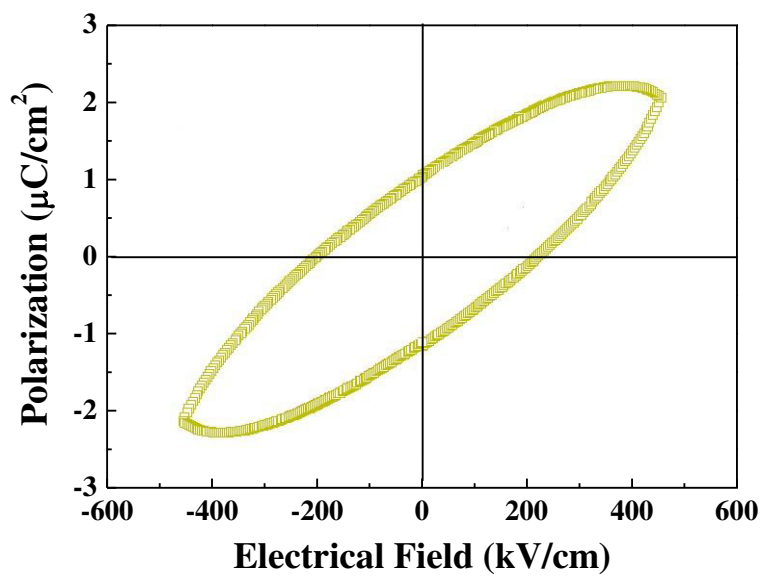

Fig. 12. Polarization versus electrical field curves of the SBN thin film deposited at $90 \mathrm{~min}$ and $125 \mathrm{~W}$.

\section{Conclusion}

In this study, high-quality $\mathrm{Sr}_{0.7} \mathrm{Ba}_{0.3} \mathrm{Nb}_{2} \mathrm{O}_{6}$ (SBN) thin films were deposited on silicon wafer using an radio frequency (RF) magnetron sputtering. When $90 \mathrm{~min}$ and $125 \mathrm{~W}$ were used as deposition time and power, the smaller leakage current density of the SBN thin film was obtained. In addition, the remnant polarization (Pr), saturation polarization (Ps), and minimum coercive field (Ec) of $1.26 \mu \mathrm{C} / \mathrm{cm}^{2}, 2.41 \mu \mathrm{C} / \mathrm{cm}^{2}$, and $201.6 \mathrm{kV} / \mathrm{cm}$, 
respectively. We demonstrated that the SBN thin film will play an important role in applications for nonvolatile memory devices.

\section{Acknowledgements}

The authors acknowledge the financial support of the Ministry of Science and Technology, R.O.C. with the contract Nos. 1052221-E-244-013- and 105-2221-E-244-014-.

\section{References}

1. M. C. Kuan, K. H. Chen, W. C. Tzou, C. M. Cheng, Y. J. Lin, Advanced Materials Research, 239-242, 2628 (2011)

2. J. Koo, J. H. Jang, B. S. Bae, J. Mater. Res., 16, 430 (2001)

3. P. B. Jamieson, S. C. Abrahams, J. L. Bernstein. J. Chem. Phys., 48, 5048 (1968)

4. A.M. Glass, J. Appl. Phys., 40, 4699 (1969)

5. J. D. Zook, S. T. Liu, J. Appl. Phys., 49, 4604 (1978)

6. S. Sakamoto, T. Yazaki, Appl. Phys. Lett., 22, 429431 (1973)

7. M. Horowitz, A. Bekker, B. Fischer, Appl. Phys. Lett., 62, 2619 (1993)

8. S. Nishiwaki, J. Takahashi, K. Kodaira, M. Kishi, Jap. J. Appl. Phys., 35, 5137 (1996)

9. Y. Xu, C. J. Chen, R. Xu, J. D. Mackenzie, Phys. Review B, 44, 35 (1991)

10. S. S. Thöny, K. E. Youden, J. S. Harris Jr., L. Hesselink, Appl. Phys. Lett., 65, 2018-2020 (1994)

11. M. Lee, R. S. Feigelson, J. Crystal Growth, 180, 220 (1997)

12. R. G. Mendes, E. B. Araújo, H. Klein, J. A. Eiras, J. Materials Sc. Letters, 8, 1941 (1999)

13. F. H. Wanga, C. F. Yang, M. C. Liu, J. Sci. Innovation, 6, 7 (2016)

14. Y. K. Wang, T. Y. Tseng, and L. Pang, Appl. Phys. Lett., 80, 3790 (2002)

15. R. Balachandran, B. H. Ong, H. Y. Wong, K. B. Tan, M. Muhamad Rasat, Inter. Jour. Electrochem. Sci., 7, 11895 (2012) 